\title{
Pathobiology of Anaplastic Large Cell Lymphoma
}

\author{
Pier Paolo Piccaluga, ${ }^{1,2}$ Anna Gazzola, ${ }^{1}$ Claudia Mannu, ${ }^{1}$ Claudio Agostinelli, ${ }^{1}$ \\ Francesco Bacci, ${ }^{1}$ Elena Sabattini, ${ }^{1}$ Carlo Sagramoso, ${ }^{1}$ Roberto Piva, ${ }^{3}$ Fernando Roncolato,, 4 \\ Giorgio Inghirami, ${ }^{3}$ and Stefano A. Pileri' ${ }^{1}$ \\ ${ }^{1}$ Hematopathology Section, Department of Hematology and Oncological Sciences "L. and A. Seràgnoli", S. Orsola-Malpighi Hospital, \\ University of Bologna, 40138 Bologna, Italy \\ ${ }^{2}$ Molecular Pathology Laboratory, Haematopathology Section, Department of Hematology and Oncological Sciences \\ "L. and A. Seràgnoli", S. Orsola-Malpighi Hospital, University of Bologna, Pavillon 8, Via Massarenti 9, 40138 Bologna, Italy \\ ${ }^{3}$ Center for Experimental Research and Medical Studies (CERMS), University of Torino, 10126 Torino, Italy \\ ${ }^{4}$ Department of Haematology, St. George Hospital, Clinical Services Building, Kogarah NSW 2217, Australia
}

Correspondence should be addressed to Pier Paolo Piccaluga, pierpaolo.piccaluga@unibo.it

Received 31 August 2010; Revised 24 November 2010; Accepted 12 December 2010

Academic Editor: Shaji Kumar

Copyright ( $) 2010$ Pier Paolo Piccaluga et al. This is an open access article distributed under the Creative Commons Attribution License, which permits unrestricted use, distribution, and reproduction in any medium, provided the original work is properly cited.

The authors revise the concept of anaplastic large cell lymphoma (ALCL) in the light of the recently updated WHO classification of Tumors of Hematopoietic and Lymphoid Tissues both on biological and clinical grounds. The main histological findings are illustrated with special reference to the cytological spectrum that is indeed characteristic of the tumor. The phenotype is reported in detail: the expression of the ALK protein as well as the chromosomal abnormalities is discussed with their potential pathogenetic implications. The clinical features of ALCL are presented by underlining the difference in terms of response to therapy and survival between the ALK-positive and ALK-negative forms. Finally, the biological rationale for potential innovative targeted therapies is presented.

\section{Introduction}

Anaplastic large cell lymphoma (ALCL) is a peripheral T-cell-derived malignancy, representing around $2 \%-3 \%$ of all lymphoid neoplasms, according to the World Health Organization (WHO) estimates $[1,2]$. Originally described by Stein et al. in 1985 [3], it has undergone a series of revisions, which have led to a more refined and restrictive definition of the process $[1,2,4,5]$. In particular, two different entities are recognized as systemic forms, the ALK ${ }^{+}$ and ALK ${ }^{-}$ALCL $[1,2,6]$, on genetic and clinical features, the first one being characterized by the deregulated expression of chimeric proteins expressing the intracytoplasmic domain of the anaplastic lymphoma kinase $(A L K)$ gene. Noteworthy, in the last edition of the WHO classification, $\mathrm{ALK}^{-} \mathrm{ALCL}$ was regarded only as a provisional entity $[1,2]$. However, emerging evidences suggest the existence of two real tumors [7]. On the other hand, differently from what initially reported by Stein et al. [3], the cutaneous variant was recognized as a different disease [8].

Primary systemic ALCL has a peak incidence in childhood, accounting for approximately $40 \%$ of NHL cases diagnosed in pediatric patients [9], whereas it accounts for $<5 \%$ of NHL in adults $[1,2,10]$, and it is seen mostly in males. Patients present with stage III to IV disease, often with multiple extranodal sites of involvement $[1,2,11,12]$.

In this article, the authors, based on their own experience and the most recent literature, review the main pathobiological features of systemic ALCL, by focusing on the molecular abnormalities representing potential targets for innovative therapies.

\section{Morphology}

According to the WHO classification, ALCL is not sustained by a unique histotype but actually includes five morphologic variants (common, giant cell-rich, lympho-histiocytic, 
small-cell type, and Hodgkin-like) [1, 2, 13, 14]. Indeed, common ALCL corresponds to the description of the tumor given by Stein and coworkers in 1985 [3].

All morphological variants are characterized by a variable proportion of large hallmark cells with eccentric horse-shoe or kidney-shaped nuclei, often with eosinophilic region near the nucleus (Figure 1). The giant cell-rich type is characterized by several multinucleated elements, often provided with Reed-Sternberg-like features and prominent intrasinusoidal diffusion $[1,5,15,16]$. The small and lympho-histiocytic variants display a marked variability of the neoplastic cell size that ranges from small to large. The main difference between the two forms is an aboundant reactive histiocytosis with eccentric nucli in the latter $[1,2,13,17-19]$. Such a reactive population tends to obscure the neoplastic component and can lead to a misdiagnosis of hyperimmune reaction $[1,2$, $13,17,18,20]$. Interestingly, transition from one histotype to the other is at times recorded within the same node (mixed variant) or in different nodes taken from the same patient at the time of diagnosis or in relapse: these modifications might correspond to intraclonal modulation or different interaction between the tumor and microenvironment [13, 21]. Further variants have been reported in the literature: signet-ring cell-like, sarcomatoid, epitheliod cell-rich, and eosinophilic-rich $[13,22,23]$. They are much rarer than the previous ones and may indeed represent a diagnostic challenge. Finally, the so-called ALCL of the Hodgkinlike type deserves special attention [24]. It was originally described as a form of the tumor, presenting in young people with a bulky mediastinal mass and consisting of anaplastic cells arranged in nodules surrounded by sclerotic bands, as seen in nodular sclerosing Hodgkin's lymphoma (NSHL) [24]. Following the introduction of the REAL Classification [5], which regarded it as a provisional entity, such diagnosis was by no means also applied to cases of aggressive HL that could not be easily differentiated from ALCL, both on morphologic and on phenotypic grounds [5]. This led to a diffuse skepticism on the existence of such variant: it was considered an undefined group more than an entity. However, bona fide examples of ALCL of the Hodgkin's-like type can be encountered. These are characterized by ALK protein-expression, homogeneous CD30-positivity, lack of CD15 and B-cell activator protein (BSAP), possible T-cell antigen expression, and variable positivity for the leukocyte common antigen/CD45 and epithelial membrane antigen (EMA) (see below).

Only basing on morphology and phenotype, the ALK ${ }^{-}$ ALCL is not reproducibly distinguishable from the $\mathrm{ALK}^{+}$ variant. The two neoplastic proliferations show, in fact, a similar morphological spectrum, although the small cell variant is not recognized in ALK ${ }^{-}$ALCL. The neoplastic cells, in $\mathrm{ALK}^{-}$ALCL tend to be larger and more pleomorphic, with higher nuclear/cytoplasmatic ratio than those seen in classical $\mathrm{ALK}^{+}$cases. This feature may suggest a diagnosis of peripheral T-cell lymphoma not otherwise specified (PTCL/NOS), but in the latter disorder, small-mediumsized lymphocytes are often admixed with a morphological homogeneous neoplastic cell proliferation and sheet-like or sinus pattern of infiltration typical of ALCL is absent. Lastly,
$\mathrm{ALK}^{-}$ALCL must be distinguished from primary cutaneous ALCL which can have a similar phenotype and morphology. Thus, the clinical correlation with staging is golden rule in those cases because primary cutaneous ALCL has a much better prognosis than $\mathrm{ALK}^{-}$ALCL.

\section{Phenotype}

Neoplastic cells of ALCL carry a distinctive phenotypic profile irrespective of the histotype $[1,2,15,25]$. They regularly express CD30 [1-3, 26] (Figure 1), a glycoprotein of $120 \mathrm{kD}$ carried by lymphoid elements following activation and formed by three distinct domains (intracytoplasmic, transmembranic, and external) $[3,26]$. It is encoded by a gene located at $1 \mathrm{p} 36$, whose activity is modulated by the number of ATCC-repeats in the $5^{\prime}$ region of the promoter, and represents a member of the receptor superfamily of tumor necrosis factor (TNF) [26]. Notably, CD30 overexpression has been reported to induce constitutive NF- $\kappa \mathrm{B}$ activation $[27,28]$. As expected, the CD30 ligand (CD30L) belongs to a group of molecules, which show homologies with TNF. The external domain of CD30 is steadily cleaved by a metalloproteinase so that it can be detected and measured in the serum [29]. At immunohistochemical analysis in both in paraffin and frozen sections, the antibodies against CD30 produce different types of positivity: membrane-bound, dotlike in the Golgi area (corresponding to the accumulation of the $90 \mathrm{kD}$ proteic precursor), and diffuse [26]. The first two patterns are exclusive to lymphoid elements with the exception of embryonic carcinoma [26], while the third one can occur in a variety of malignant tumors other than lymphomas, including pancreas carcinoma, naso-pharyngeal undifferentiated carcinoma, mesothelioma, and malignant melanoma [26]. Therefore, the immunophenotypic diagnosis of ALCL should always be based on the application of a panel of antibodies, including reagents anticytokeratins, melanoma-associated antigens, CEA, and PLAP $[1,2]$. In $60 \%-70 \%$ of cases, ALCL carries the epithelial membrane antigen (EMA) (Figure 1): this molecule is more easily detected in Bouin-fixed samples [13, 30]. CD3 expression is appreciated in about half cases: it usually occurs at the cytoplasmic level as expected in activated cells [13, 31]. All T-cell associated antigens should be explored, as CD3 negative tumors may carry CD2, CD5, and/or CD7 [13, $15,31-33]$. The expression of CD4 and CD8 is variable $[13,15]$. Positivity for TIA-1, granzyme B, and perforin is recorded in about $85 \%$ of instances (Figure 1). NKantigens have at times been detected, in both spontaneous and experimental tumors [34,35]. About $20 \%$ of ALCLs lack CD45 and/or express CD15 [13] (Figure 1). Notably, BSAP (i.e., the PAX5 gene product) is absent [36]: its search represents a very useful tool for the differentiation of ALCL from common HL and DLBCL, which are both BSAPpositive [36]. The recent development of antibodies against the anaplastic large cell lymphoma kinase (ALK) has further refined the immunohistochemical analysis of ALCL $[13,15$, 17, 37] (Figure 1). In fact, expression of this molecule does characteristically occur in cases carrying translocations that involve the corresponding gene (see below) $[13,15,17,37]$ 
GM-1

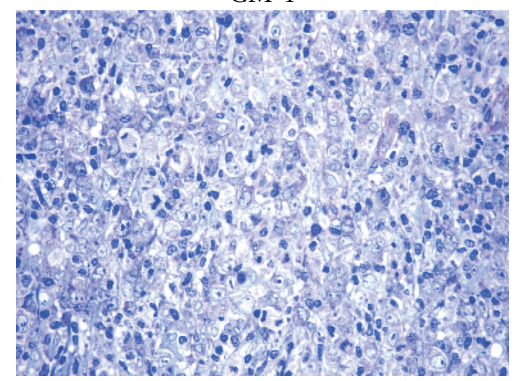

(a)

CD30

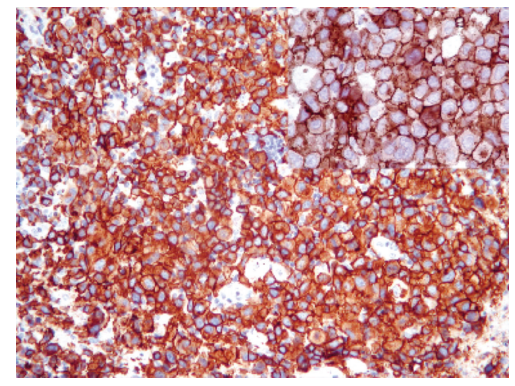

(c)

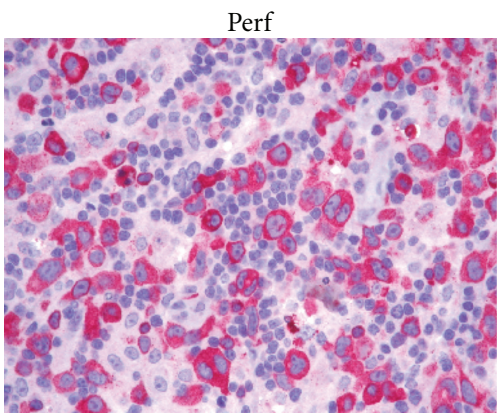

(e)

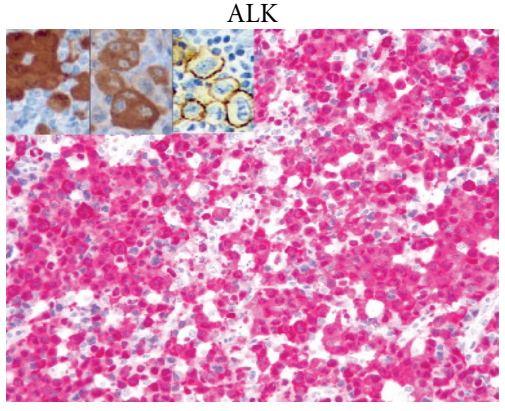

(g)
GM-2

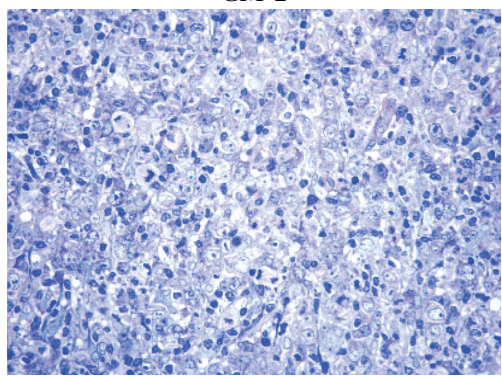

(b)

CD45

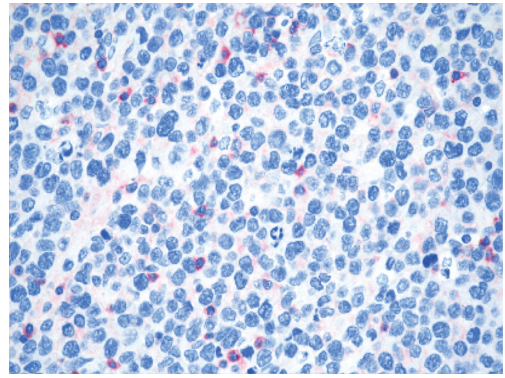

(d)

EMA

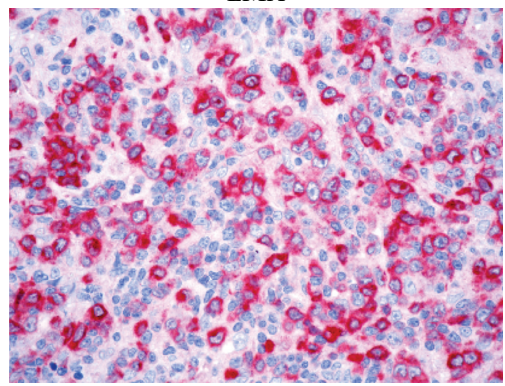

(f)

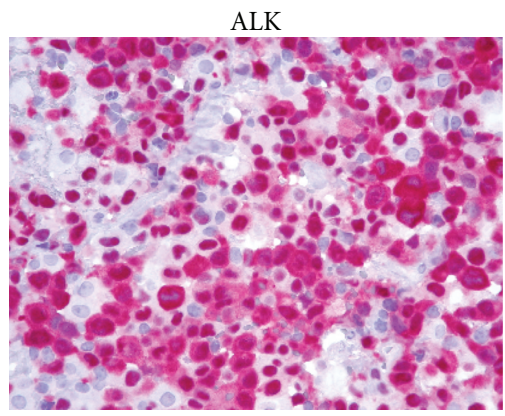

(h)

Figure 1: Morphological and immunophenotypical features of ALCL. At morphology (GM), a variable amount of hallmark cells can be identified, the phenotype being typically $\mathrm{CD} 30^{+}$, and possibly $\mathrm{CD}_{4} 5^{-}, \mathrm{EMA}^{+}$, and Perforin (Perf) ${ }^{+}$. In $\mathrm{ALK}^{+}$cases, $\mathrm{ALK}$ staining more frequently interests both nucleus and cytoplasm, being associated with NMP1/ALK translocation. However, different transcripts may determine an isolated cytoplasmic or membranous staining (see insets; refer to Table 1 for details).

(Table 1). In principle, the most common $t(2 ; 5)$ causes strong positivity of the neoplastic cells at the cytoplasmic and nuclear levels, while the other translocations produce accumulation of the protein in the cytoplasm. These different staining patterns correspond to over-expression of the $A L K$ gene product: they bear diagnostic relevance, since ALK is detected neither in normal lymphocytes nor in $\operatorname{HL}[17,38]$. Of note, such kinase has been identified in some lymphoid 
TABLE 1: Main translocation involving ALK recorded in anaplastic large cell lymphoma.

\begin{tabular}{|c|c|c|c|c|}
\hline Chromosomal translocation & Partner gene & Fusion gene & Frequency (5) & ALK IHC detection \\
\hline $\mathrm{t}(2 ; 5)(\mathrm{p} 23 ; \mathrm{q} 35)$ & NPM1 & NPM1/ALK & $75-80$ & Cytoplasmic/nuclear \\
\hline $\mathrm{t}(1 ; 2)(\mathrm{q} 25 ; \mathrm{p} 23)$ & TMP3 & TMP3/ALK & $12-18$ & Cytoplasmic \\
\hline $\operatorname{inv}(2)$ & ATIC & ATIC/ALK & 2 & Cytoplasmic \\
\hline $\mathrm{t}(2 ; 3)(\mathrm{p} 23 ; \mathrm{q} 21)$ & $T G F$ & $T G F / A L K$ & 2 & Cytoplasmic \\
\hline $\mathrm{t}(2 ; 17)(\mathrm{p} 23 ; \mathrm{q} 23)$ & CLTL & CLTL/ALK & 2 & Cytoplasmic \\
\hline $\mathrm{t}(2 ; 17)(\mathrm{p} 23 ; \mathrm{q} 25)$ & ALO17 & $A L O 17 / A L K$ & $<1$ & Cytoplasmic \\
\hline $\mathrm{t}(2 ; 19)(\mathrm{p} 23 ; \mathrm{p} 13)$ & TPM4 & $T P M 4 / A L K$ & $<1$ & Cytoplasmic \\
\hline $\mathrm{t}(2 ; 22)(\mathrm{p} 23 ; \mathrm{q} 11.2)$ & МYH9 & MYH9/ALK & $<1$ & Cytoplasmic \\
\hline $\mathrm{t}(2 ; \mathrm{X})(\mathrm{p} 23 ; \mathrm{q} 11-12)$ & $M S N$ & $M S N / A L K$ & $<1$ & Membranous \\
\hline
\end{tabular}

NPM1: nucleophosmin; ALK: anaplastic lymphoma kinase; TPM3: tropomyosin 3; ATIC: 5-aminoimidazole-4-carboxamide ribonucleotide formyltransferase/IMP cyclohydrolase; TGF: TRK-fused gene; CLTL: Clathrin heavy chainlike 1; ALO17: ALK lymphoma oligomerization partner on chromosome 17; TPM4: tropomyosin 4; MYH9: Nonmuscle myosin heavy chain; MSN: moesin; IHC: immunohistochemistry.

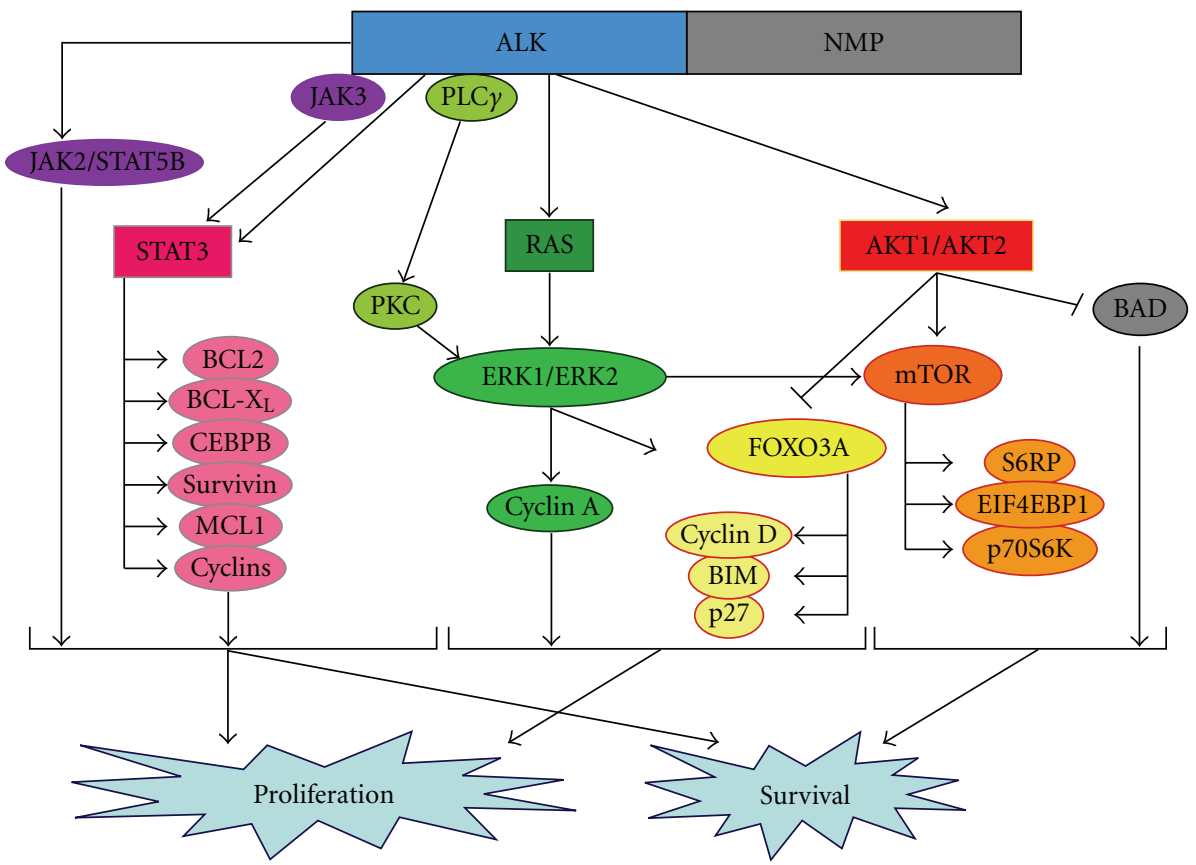

FIGURE 2: Schematic representation of ALK signalling. In particular, ALK signalling promotes tumor cell proliferation and survival via STAT3, RAS/ERK, and AKT/mTOR pathways. Noteworthy, the blockage of the signalling was demonstrated to have significant antitumor activity in experimental models of ALK ${ }^{+}$ALCL.

and nonlymphoid neoplasms that have nothing in common with ALCL [38]. In particular, it can occur-more often at the cytoplasmic level-in B-plasmablastic lymphomas bearing a distinctive phenotype $\left(\mathrm{ALK}^{+}, \mathrm{CD} 138^{+}, \mathrm{EMA}^{+}\right.$, $\mathrm{IgA}^{+/-}, \mathrm{Bcl}-2$ protein $^{+/-}, \mathrm{CD}^{-/+}, \mathrm{CD}^{2} 7^{-/+}, \mathrm{CD}^{-0^{-}}, \mathrm{CD}^{-}$, and $\mathrm{CD}^{-} 0^{-}$): like ALCL, these tumors do also carry cytogenetic abnormalities involving the $A L K$ gene [38]. Among nonhaematopoietic neoplasms, ALK positivity is found in inflammatory myofibroblastic tumour (IMT) and some neuroblastomas and rhabdomyosarcomas and carcinomas $[39,40]$. Interestingly, it has been shown that ALK has immunogenic properties, thus causing the production of antibodies that can be easily detected in the serum and might be relevant to the relatively good prognosis of $\mathrm{ALK}^{+}$ ALCL [41]. These immunogenic properties should be taken into account for two additional reasons: (1) they might be employed for vaccination strategies [42] and (2) they might cause extensive tumor destruction, hypocellularity, and oedema of the affected nodes, thus mimicking an inflammatory lesion [43]. Notably, ALK expression is felt to play a relevant role in the process of lymphomagenesis, as suggested by experimental data [44-46]. In this respect, experimental and in vivo studies have provided evidence that the chimeric protein NPM/ALK secondary to $t(2 ; 5)$ causes profound deregulation of cell kinetics. In fact, it determines phosphorylation of JAK3 and/or direct STAT3 activation: the later induces expression of TIMP1 and $\mathrm{Bcl}-\mathrm{X}_{\mathrm{L}}$ and $\mathrm{Bcl}-$ A2 that in turn with increased activated caspase-3 levels contributes to the activation of the antiapoptotic pathway [46] (Figure 2). In addition, the NPM/ALK chimeric protein 
facilitates proliferation via activation of a series of factors, including PLC- $\gamma$, type IA phosphoinositide 3-kinase, Srckinases, AKT, and FOXO3a [23] (Figure 2). Interestingly, the above mentioned cell-kinetic alterations are not observed to the same extent in many ALK ${ }^{-}$ALCLs, a fact that further supports the distinction of ALK-positive and negative cases. In line with this, the different expression of the lymphocyte specific protein (LSP1) detected in all ALK ${ }^{+}$ALCLs and only $25 \%$ of the negative ones [47]. Conversely, expression of retinoblastoma protein and survivin can occur in both $\mathrm{ALK}^{+}$ and $\mathrm{ALK}^{-}$ALCLs, in any case representing independent unfavorable prognostic indicators $[48,49]$.

Finally, the search for Epstein-Barr virus (EBV) is negative in most if not all ALCLs both by in situ hybridization (ISH) by and immunohistochemistry: such negativity is regarded as one of the distinguishing features between ALCL and HL in controversial cases [50]. Recently, however, occasional $\mathrm{ALK}^{+}$ALCLs showing EBV integration in their genome have been reported: they occurred in patients with a previous history of solid organ transplant [51].

\section{Molecular Genetics}

The $t(2 ; 5)(\mathrm{p} 23 ; \mathrm{q} 35)$ was originally described in examples of malignant histiocytosis (MH) [52]. These actually represented ALCL cases diagnosed according to dated criteria. In fact, it quickly became evident that such translocations characteristically occurred in ALCL [53-56]. At the beginning, the real incidence of the phenomenon was uncertain: in fact, the need for fresh or frozen material for cytogenetic studies or Southern blot analysis prevented its systemic search. In principle, the aberration produced the development of a hybrid gene, formed by the segment of the ALK gene encoding for the transmembrane portion of the corresponding kinase and the $\mathrm{NH}_{2}$-terminal region of the NPM1 gene $[38,57]$. Under physiologic conditions, the latter encodes for nucleophosmin, that is, a shuttleprotein that undergoes dimerization in the cytoplasm and subsequently moves to the nucleus [58]. Thanks to the production of highly specific (polyclonal and monoclonal) antibodies against the transmembrane domain of the ALK protein, as well as the $\mathrm{NH}_{2}$ - and $\mathrm{COOH}$-terminal regions of NPM, the identification of the chimeric NPM/ALK protein (also termed p 80 because of its molecular weight) became easily feasible in routine (formalin-fixed, paraffinembedded) samples $[17,37,59]$. The resulting assessment demonstrated that the large majority of cases diagnosed as ALCL according to the REAL/WHO Classification do indeed carry $t(2 ; 5)[55,60]$. The staining produced by the antiALK antibodies is typically cytoplasmic and nuclear: this is due to the fact that the NPM/ALK protein forms heterodimers with normal NPM and-like normal NPM homodimersis shuttled to the nucleus $[37,60,61]$ (Figure 1). Unexpectedly, the broad application of the monoclonal antibodies ALK1 and $\mathrm{ALK}_{\mathrm{c}}$ revealed that about $10 \%$ of $\mathrm{ALK}^{+}$ALCLs showed an immunohistochemical reactivity confined to the cytoplasm. This was concomitant with the detection of a series of additional translocations (commonly called variant translocations), all involving the $A L K$ gene, but leading to the formation of a chimeric gene with partners other than NPM1 [38, 62] (Figure 1). The derived hybrid proteins-all leading to deregulated expression of ALK fusion proteinsare more often under oligomerization but have not shuttling properties, thus remaining confined to the cytoplasm [38]. The most relevant of these variant translocations are listed in Table 1.

Interestingly, one of these variants, $t(2 ; 17)(\mathrm{p} 23 ; \mathrm{q} 23)$, is also observed in IMT as well as in B-plasmablastic lymphoma [63, 64], while $\mathrm{t}(1 ; 2)(\mathrm{q} 25 ; \mathrm{p} 23), \mathrm{t}(2 ; 19)(\mathrm{p} 23 ; \mathrm{p} 13)$, and $t(2 ; 11 ; 2)(\mathrm{p} 23 ; \mathrm{p} 15 ; \mathrm{q} 31)$ are detected more frequently in IMT than in ALCL [63]. Conversely, with the exception of two studies, which results could not be reproduced in other labs, neither ALK protein detection nor $\mathrm{t}(2 ; 5)$ or variant translocations have been detected in HL [65].

Recently, by using a comparative genomic hybridization (CGH) platform, Salaverria et al. [66] identified chromosomal imbalances in $58 \%$ of $\mathrm{ALK}^{+}$ALCL and in $65 \%$ of $\mathrm{ALK}^{-}$ cases, within a cohort of 74 cases $\left(43 \mathrm{ALK}^{+}\right.$and $31 \mathrm{ALK}^{-}$, resp.). Importantly, ALCL carrying NPM1-ALK or other translocations involving $A L K$ showed a similar profile of genetic alterations. In particular, recurrent gains of $17 \mathrm{p}$ and $17 \mathrm{q} 24$ and losses of 4q13-q21 and 11q14 were found in ALK ALCL. On the other hand, gains of $1 \mathrm{q}$ and $6 \mathrm{p} 21$ were more frequently observed in $\mathrm{ALK}^{-}$forms [66]. Thus, CGH data confirmed that $\mathrm{ALK}^{+}$and $\mathrm{ALK}^{-}$ALCL are different genetic diseases, though few recurrent chromosomal imbalances were found in both types of tumors (gains of 7 and $6 \mathrm{q}$ and $13 \mathrm{q}$ losses), confirming that all ALCLs probably share common pathogenetic events (see below) $[67,68]$.

4.1. Gene Expression Profiling. Regarding gene expression profiling (GEP), Thompson et al. [67] initially demonstrated the ability of GEP to correctly distinguish between $\mathrm{ALK}^{+}$and ALK $^{-}$ALCL based on the analysis of their transcriptome. Importantly, in this study it was also suggested that some pathogenetic mechanisms might be shared by these two entities, based on the common expression of certain genes in both $\mathrm{ALK}^{+}$and $\mathrm{ALK}^{-}$cases.

Subsequently, the study by Lamant et al. [69] confirmed that the different morphological variants of ALCL (common type, small cell, and "mixed" variants) could be distinguished based on the expression of specific genes. Moreover, it was shown that $\mathrm{ALK}^{+}$and $\mathrm{ALK}^{-}$ALCL have different molecular signatures. Specifically, within the molecular signature of $\mathrm{ALK}^{+}$ALCL BCL6, CEBPB, SERPINA1, and PTPN12 were found to be overexpressed, some of these data being further validated by immunohistochemistry on tissue microarrays. Conversely, $\mathrm{ALK}^{-}$ALCLs were found to overexpress CCR7, CNTFR, IL22, and IL21. Overall, this study strongly supported the concept that $\mathrm{ALK}^{+}$and $\mathrm{ALK}^{-} \mathrm{ALCL}$ are different entities but did not provide novel information as far as the molecular pathogenesis of $\mathrm{ALK}^{-}$ALCL was concerned.

Our group then included some ALCL in a GEP study on PTCLs [68]. Interestingly, we found that ALCL can be roughly distinguished from other PTCLs irrespectively of the ALK status, confirming the idea of common pathogenetic events. Finally, additional important information has been then offered by Piva et al. [70]. In this study, we have mainly 
focused on the molecular pathogenesis of ALCL but also established the relationship between ALCL and PTCL/NOS. In particular, we showed that ALCLs are molecularly distinct from PTCL/NOS. Significantly, a predictive analysis allowed identification of 34 probe sets capable of distinguishing ALCL from other T-NHL, suggesting that ALCLs share important biopathological features. Furthermore, it was possible to clearly differentiate $\mathrm{ALK}^{+}$and $\mathrm{ALK}^{-}$cases according to their GEPs, based on the expression of selected genes, including GAS1, an ALK dependent molecule [7]. Finally, we demonstrated the strong biological relevance of the ALK/STAT3 signaling in characterizing the global molecular profile of ALK ${ }^{+}$ALCL [70].

More recently, Eckerle et al. [33] studied isolated cells from ALCL cases. Interestingly, the analysis supported the derivation of ALCL from activated T cells, though it was not possible to identify a specific counterpart [33]. Surprisingly, the authors found that only few genes were differentially expressed between systemic and cutaneous ALCL despite their different clinical behavior, and between ALK ${ }^{-}$ALCL and classical Hodgkin lymphoma, despite their different cellular origin [33].

4.2. Besides the NPM-ALK Chimera. Besides the NPM-ALK chimera several other fusions of ALK have been described in lymphoid neoplasms and more recently in epithelial cancers. Among them, TFG gene (TFG-ALKS (short), TFGALKL (long), and TFG-ALKXL (extra long)) have been described [38]. In these translocations, different length fragments of the $5^{\prime}$ TFG region, all of them containing the TFG coiled-coil oligomerization domain, are fused with the intracytoplasmic domain of ALK, which drives the constitutive ALK kinase activation. Since the TFG-ALK fusion proteins lack nuclear localization, signals are mainly confined to the cytoplasmic compartment. Analogously, the translocation $\mathrm{t}(1 ; 2)(\mathrm{p} 23 ; \mathrm{q} 21)$ leads to translation of an another cytoplasmic ALK fusion protein in which the NH-2 terminus region of TPM3 is linked to the intracytoplasmic domain of ALK. ALK fusions also occur with TPM4, a homolog of TPM3, and both TPM3- and TPM4-ALK proteins lead to the constitutive autophosphorylation of ALK as a result of homodimerization through the TPM coiled-coil domains [38].

ATIC, CLTCL and MSN-ALK are also nonnuclear ALK fusion chimeras. In ATIC-ALK, the 5-aminoimidazole-4carboxamide ribonucleotide formyltransferase/IMP cyclohydrolase (ATIC) gene, located within chromosome 2, which catalyzes steps of de novo purine nucleotide biosynthesis, is fused to ALK as a result of cryptic inversion $\operatorname{inv}(2)$ 9p23q35 [38]. ALK can be fused to the CLTCL (clathrin heavy polypeptide-like) gene $(17 q 23)$ and CLTCL-ALK proteins display a typical cytoplasmic dot-like expression pattern reflecting an ALK-positive polyhedral coat on the surface of vesciles [38]. Finally two other translocations, the $t(2 ; 17)(p 23 ; q 25)$ and the $t(2 ; 22)(p 23 ; q 11.2)$, lead to the translation of AL017- and MYH9-ALK chimera which localized within the cytoplasms. A different cell localization is documented for the moesin- (MSN-) ALK fusion protein, whose restricted surface membrane distribution is probably attributable to association with wild-type MSN and other membrane proteins. MSN-ALK does not contain an oligomerization domain in its N-terminal domain.

Despite different structural and cellular localization all ALK fusion proteins have very similar transforming properties in vitro and no clear clinical differences have been so far described.

Together, these findings tend to suggest that the transforming properties of ALK fusion could be due to their cytoplamic localization and/or to activation of multiple downstream molecules primarily localized within the cytoplasmic compartment.

\section{Clinical Behavior}

ALCL is an aggressive lymphoma which frequently presents in advanced clinical stage (III-IV) with systemic symptoms, and extranodal involvement, as other PTCLs do [15, 60]. Bone marrow involvement is detected in up to $30 \%$ of cases, being a relevant prognostic feature [71-73].

Importantly, ALCLs display quite different clinical features depending on the expression of the ALK protein [6, $15,60,74-76]$. In particular, $\mathrm{ALK}^{+}$tumors most frequently occur among patients in the first or second decade of life, while $\mathrm{ALK}^{-}$ones are usually recorded among people aged 50-70 [6, 15, 60]. Moreover, advanced-stage disease and $\mathrm{B}$ symptoms are slightly more common in $\mathrm{ALK}^{+} \mathrm{ALCL}$ $[6,15]$. Most importantly, several studies have shown that $\mathrm{ALK}^{+}$has a significantly better outcome than ALK ${ }^{-}$ALCL. In particular, up to $90 \%$ of $\mathrm{ALK}^{+}$ALCLs achieve complete remission (CR) by adopting standard antracyclin-containing regimens, and $70 \%-80 \%$ of patients were actually cured $[6$, $15,60,74-76]$. By contrast, only around $30 \%-50 \%$ of $\mathrm{ALK}^{-}$ cases obtain stable CR by the same therapies $[6,15,60]$, suggesting that more aggressive strategies including autologous or allogenic bone-marrow/stem cell transplantation may be necessary [77]. Interestingly, leukemic spread seems to represent a major exception to the favorable prognosis of ALK $^{+}$ALCL $[6,15,60,72]$.

Noteworthy, the International T-cell lymphoma project has recently reported that $\mathrm{ALK}^{+}$and $\mathrm{ALK}^{-} \mathrm{ALCL}$ seem to have a similar prognosis (in terms of both FFS and OS), when patients are stratified according to the clinical parameters (i.e., age and/or stage). Grippingly, this would suggest a prominent role for clinical factors in determining patients outcome, rather than for biological components [6].

Notably, in the past years, it was suggested that the distinction between $\mathrm{ALK}^{-}$ALCL and peripheral T-cell lymphoma, not otherwise specified (PTCL/NOS), was of limited clinical relevance, only age and the International Prognostic Index (IPI) being of prognostic relevance in these tumors [78]. Nevertheless, it was recently shown that clinical differences do exist between the two entities. In particular, in a large international study, a greater proportion of patients with poor performance status and B symptoms, but a lower frequency of bone marrow invasion, splenic involvement, and thrombocytopenia, was observed with $\mathrm{ALK}^{-}$ALCL as compared to PTCL/NOS [6]. Indeed, in this study, 
$\mathrm{ALK}^{-}$ALCL showed an overall outcome significantly better than PTCL/NOS [6].

\section{Targeted Therapy}

Despite the recent significant progresses in understanding the molecular pathogenesis of ALCL, the therapeutic approaches are still based on doxorubicin-containing combination chemotherapy [6]. However, the fact that NPM-ALK plays a central role in the development and progression of $\mathrm{ALK}^{+}$ALCL tumors makes it an ideal candidate therapeutic target in this disease. Notably, the wt ALK protein is not widely expressed in adult tissues, being abundant only in a few neuronal cells. Therefore, few toxic effects might be expected from treatment aimed at blocking ALK function. Remarkably, the administration of selective inhibitors induced tumor growth arrest and possibly its regression in vivo $[79,80]$. More recently, ALK was shown to be an ideal candidate target for antitumor vaccination. Indeed, in ALCL xenograft models, such strategy completely prevented tumor growth and increased the percentages of cured mice when combined with chemotherapy [42].

Additionally, the JAK/STAT and the PI3K/AKT have been recently proposed as potential targets in $\mathrm{ALK}^{+}$lymphomas $[46,81,82]$. Similarly, the blockage of their activation by interfering with the upstream cytokines and growth factors has been shown to be potentially effective [83]. Importantly, as tyrosine-kinase deregulation has been documented in several other T-NHLs $[68,84-86]$, it is conceivable that $\mathrm{ALK}^{-}$ALCL might present similar phenomenon as well, further studies being indeed warranted.

Finally, immunotherapy strategies could represent another possible therapeutic approaches. In particular, in vitro and in vivo studies showed that antiCD30 antibodies induce apoptotic cell death and tumor regression in $\mathrm{CD} 30^{+}$lymphomas, including ALCL [87-91]. In addition, other studies have suggested that CD26 might represent a promising immunotherapeutic target [92].

\section{Conclusion}

In conclusion, based on the most recent findings, the WHO classification currently considers two ALCL types, ALK ${ }^{+}$ and $\mathrm{ALK}^{-}$. In fact, though the latter is still quoted as a provisional entity, increasing evidence, both biological and clinical, suggests the real existence of two distinct, though similar, tumors. ALK represents an ideal therapeutic target for innovative strategies, including small inhibiting molecules and even vaccination. On the other hand, ALK ${ }^{-}$ cases may benefit, in the future, from monoclonal antibodies (i.e., antiCD30), tyrosine-kinase inhibitors, or other signal transduction inhibitors.

\section{Financial Disclosure}

The authors have no conflicting financial interests to declare.

\section{Acknowledgments}

This work was supported by Centro Interdipartimentale per la Ricerca sul Cancro "G. Prodi", BolognAIL, Ateneo 60\% (Professor S.A. Pileri), FIRB (Professor S.A. Pileri and Professor P.L. Zinzani), Associazione Italiana per la Ricerca sul Cancro (AIRC, IG10007 and Professor G. Inghirami, and R.Piva), Fondazione CARISBO, Progetto Strategico d'Ateneo (Professor S.A. Pileri/Dr. PP Piccaluga) grants, Fondazione Guido Berlucchi (Professor G. Inghirami); Ministero dell'Università e Ricerca Scientifica (MIUR, Professor G. Inghirami); Regione Piemonte; Compagnia di San Paolo, Torino (Progetto Oncologia, Professor G. Inghirami); and Sixth Research Framework Program of the European Union, Project RIGHT (LSHB-CT-2004-005276, Professor G. Inghirami). G. Inghirami and S.A. Pileri equally contributed to this article.

\section{References}

[1] G. Delsol, E. S. Jaffe, B. Falini et al., "Anaplastic large cell lymphoma (ALCL), ALK-positive," in WHO Classification of Tumors of Hematopoietic and Lymphoid Tissues, S. Swerdlow, E. Campo, and N. L. Harris, Eds., pp. 312-316, IARC, Lyon, France, 4th edition, 2008.

[2] D. Y. Mason, N. L. Harris, G. Delsol et al., "Anaplastic large cell lymphoma, ALK-negative," in WHO Classification of Tumors of Hematopoietic and Lymphoid Tissues, S. Swerdlow, E. Campo, N. L. Harris et al., Eds., pp. 317-319, IARC, Lyon, France, 4th edition, 2008.

[3] H. Stein, D. Y. Mason, and J. Gerdes, "The expression of the Hodgkin's disease associated antigen $\mathrm{Ki}-1$ in reactive and neoplastic lymphoid tissue: evidence that Reed-Sternberg cells and histiocytic malignancies are derived from activated lymphoid cells," Blood, vol. 66, no. 4, pp. 848-858, 1985.

[4] A. G. Stansfeld, J. Diebold, H. Noel et al., "Updated Kiel classification for lymphomas," Lancet, vol. 1, no. 8580, pp. 292-293, 1988.

[5] N. L. Harris, E. S. Jaffe, H. Stein et al., "A revised EuropeanAmerican classification of lymphoid neoplasms: a proposal from the International Lymphoma Study Group," Blood, vol. 84, no. 5, pp. 1361-1392, 1994.

[6] K. J. Savage, N. L. Harris, J. M. Vose et al., "ALK anaplastic large-cell lymphoma is clinically and immunophenotypically different from both ALK ALCL and peripheral T-cell lymphoma, not otherwise specified: report from the International Peripheral T-Cell Lymphoma Project," Blood, vol. 111, no. 12, pp. 5496-5504, 2008.

[7] R. Piva, L. Agnelli, E. Pellegrino et al., "Gene expression profiling uncovers molecular classifiers for the recognition of anaplastic large-cell lymphoma within peripheral T-cell neoplasms," Journal of Clinical Oncology, vol. 28, no. 9, pp. 1583-1590, 2010.

[8] E. Ralfkiaer, R. Willemze, M. Paulli, and M. Kadin, "Primary cutaneous CD30-positive T-cell lymphoproliferative disorders," in WHO Classification of Tumors of Hematopoietic and Lymphoid Tissues, S Swerdlow, E Campo, N. L. Harris et al., Eds., pp. 300-301, IARC, Lyon, France, 4th edition, 2008.

[9] J. T. Sandlund, C. H. Pui, W. M. Roberts et al., "Clinicopathologic features and treatment outcome of children with largecell lymphoma and the $\mathrm{t}(2 ; 5)(\mathrm{p} 23 ; \mathrm{q} 35)$," Blood, vol. 84, no. 8 , pp. 2467-2471, 1994. 
[10] M. E. Kadin and S. W. Morris, "The $\mathrm{t}(2 ; 5)$ in human lymphomas," Leukemia and Lymphoma, vol. 29, no. 3-4, pp. 249-256, 1998.

[11] M. A. Rizvi, A. M. Evens, M. S. Tallman, B. P. Nelson, and S. T. Rosen, “T-cell non-Hodgkin lymphoma," Blood, vol. 107, no. 4, pp. 1255-1264, 2006.

[12] K. J. Savage, "Peripheral T-cell Lymphomas," Blood Reviews, vol. 21, no. 4, pp. 201-216, 2007.

[13] D. Benharroch, Z. Meguerian-Bedoyan, L. Lamant et al., "ALK-positive lymphoma: a single disease with a broad spectrum of morphology," Blood, vol. 91, no. 6, pp. 2076-2084, 1998.

[14] E. S. Jaffe, "Anaplastic large cell lymphoma: the shifting sands of diagnostic hematopathology," Modern Pathology, vol. 14, no. 3, pp. 219-228, 2001.

[15] H. Stein, H. D. Foss, H. Durkop et al., "CD30+ anaplastic large cell lymphoma: a review of its histopathologic, genetic, and clinical features," Blood, vol. 96, no. 12, pp. 3681-3695, 2000.

[16] M. E. Kadin, "Anaplastic large cell lymphoma and its morphological variants," Cancer Surveys, vol. 30, pp. 77-86, 1997.

[17] B. Falini, B. Bigerna, M. Fizzotti et al., "ALK expression defines a distinct group of T/null lymphomas ("ALK lymphomas") with a wide morphological spectrum," American Journal of Pathology, vol. 153, no. 3, pp. 875-886, 1998.

[18] S. A. Pileri, K. Pulford, S. Mori et al., "Frequent expression of the NPM-ALK chimeric fusion protein in anaplastic largecell lymphoma, lympho-histiocytic type," American Journal of Pathology, vol. 150, no. 4, pp. 1207-1211, 1997.

[19] M. C. Kinney, R. D. Collins, J. P. Greer, J. A. Whitlock, N. Sioutos, and M. E. Kadin, "A small-cell-predominant variant of primary Ki-1 (CD30) ${ }^{+}$T-cell lymphoma," American Journal of Surgical Pathology, vol. 17, no. 9, pp. 859-868, 1993.

[20] P. P. Piccaluga, S. Ascani, G. F. Orcioni et al., "Anaplastic lymphoma kinase expression as a marker of malignancy. Application to a case of anaplastic large cell lymphoma with huge granulomatous reaction," Haematologica, vol. 85, no. 9, pp. 978-981, 2000.

[21] K. B. Hodges, R. D. Collins, J. P. Greer, M. E. Kadin, and M. C. Kinney, "Transformation of the small cell variant $\mathrm{Ki}-1^{+}$ lymphoma to anaplastic large cell lymphoma: pathologic and clinical features," American Journal of Surgical Pathology, vol. 23, no. 1, pp. 49-58, 1999.

[22] J. K. C. Chan, R. Buchanan, and C. D. M. Fletcher, "Sarcomatoid variant of anaplastic large-cell Ki-1 lymphoma," American Journal of Surgical Pathology, vol. 14, no. 10, pp. 983-988, 1990.

[23] A. Fornari, R. Piva, R. Chiarle, D. Novero, and G. Inghirami, "Anaplastic large cell lymphoma: one or more entities among T-cell lymphoma?” Hematological Oncology, vol. 27, no. 4, pp. 161-170, 2009.

[24] J. Vassallo, L. Lamant, L. Brugieres et al., "ALK-positive anaplastic large cell lymphoma mimicking nodular sclerosis Hodgkin's lymphoma: report of 10 cases," American Journal of Surgical Pathology, vol. 30, no. 2, pp. 223-229, 2006.

[25] B. Falini, "Anaplastic large cell lymphoma: pathological, molecular and clinical features," British Journal of Haematology, vol. 114, no. 4, pp. 741-760, 2001.

[26] B. Falini, S. Pileri, G. Pizzolo et al., "CD30 (Ki-1) molecule: a new cytokine receptor of the tumor necrosis factor receptor superfamily as a tool for diagnosis and immunotherapy," Blood, vol. 85, no. 1, pp. 1-14, 1995.
[27] R. Horie, T. Watanabe, Y. Morishita et al., "Ligandindependent signaling by overexpressed CD30 drives NF- $\kappa \mathrm{B}$ activation in Hodgkin-Reed-Sternberg cells," Oncogene, vol. 21, no. 16, pp. 2493-2503, 2002.

[28] C. W. Wright, J. M. Rumble, and C. S. Duckett, "CD30 activates both the canonical and alternative NF- $\kappa \mathrm{B}$ pathways in anaplastic large cell lymphoma cells," Journal of Biological Chemistry, vol. 282, no. 14, pp. 10252-10262, 2007.

[29] O. Josimovic-Alasevic, H. Durkop, R. Schwarting, E. Backe, H. Stein, and T. Diamantstein, "Ki-1 (CD30) antigen is released by Ki-1-positive tumor cells in vitro and in vivo. I. Partial characterization of soluble Ki-1 antigen and detection of the antigen in cell culture supernatants and in serum by an enzyme-linked immunosorbent assay," European Journal of Immunology, vol. 19, no. 1, pp. 157-162, 1989.

[30] G. Delson, T. Al Saati, K. C. Gatter et al., "Coexpression of epithelial membrane antigen (EMA), Ki-1, and interleukin2 receptor by anaplastic large cell lymphomas. Diagnostic value of so-called malignant histiocytosis," American Journal of Pathology, vol. 130, no. 1, pp. 59-70, 1988.

[31] I. Bonzheim, E. Geissinger, S. Roth et al., "Anaplastic large cell lymphomas lack the expression of T-cell receptor molecules or molecules of proximal T-cell receptor signaling," Blood, vol. 104, no. 10, pp. 3358-3360, 2004.

[32] T. S. Barry, E. S. Jaffe, L. Sorbara, M. Raffeld, and S. Pittaluga, "Peripheral T-cell lymphomas expressing CD30 and CD15," American Journal of Surgical Pathology, vol. 27, no. 12, pp. 1513-1522, 2003.

[33] S. Eckerle, V. Brune, C. Döring et al., "Gene expression profiling of isolated tumour cells from anaplastic large cell lymphomas: insights into its cellular origin, pathogenesis and relation to Hodgkin lymphoma," Leukemia, vol. 23, no. 11, pp. 2129-2138, 2009.

[34] H. D. Foss, I. Anagnostopoulos, I. Araujo et al., "Anaplastic large-cell lymphomas of T-cell and null-cell phenotype express cytotoxic molecules," Blood, vol. 88, no. 10, pp. 4005-4011, 1996.

[35] L. Krenacs, A. Wellmann, L. Sorbara et al., "Cytotoxic cell antigen expression in anaplastic large cell lymphomas of Tand null-cell type and Hodgkin's disease: evidence for distinct cellular origin," Blood, vol. 89, no. 3, pp. 980-989, 1997.

[36] C. Agostinelli, E. Sabattini, J. O. Gjørret et al., "Characterization of a new monoclonal antibody against PAX5/BASP in 1525 paraffin-embedded human and animal tissue samples," Applied Immunohistochemistry \& Molecular Morphology, vol. 18, no. 6, pp. 561-572, 2010.

[37] K. Pulford, L. Lamant, S. W. Morris et al., "Detection of anaplastic lymphoma kinase (ALK) and nucleolar protein nucleophosmin (NPM)-ALK proteins in normal and neoplastic cells with the monoclonal antibody ALK1," Blood, vol. 89, no. 4, pp. 1394-1404, 1997.

[38] R. Chiarle, C. Voena, C. Ambrogio, R. Piva, and G. Inghirami, "The anaplastic lymphoma kinase in the pathogenesis of cancer," Nature Reviews Cancer, vol. 8, no. 1, pp. 11-23, 2008.

[39] C. A. Griffin, A. L. Hawkins, C. Dvorak, C. Henkle, T. Ellingham, and E. J. Perlman, "Recurrent involvement of 2p23 in inflammatory myofibroblastic tumors," Cancer Research, vol. 59, no. 12, pp. 2776-2780, 1999.

[40] B. Lawrence, A. Perez-Atayde, M. K. Hibbard et al., "TPM3ALK and TPM4-ALK oncogenes in inflammatory myofibroblastic tumors," American Journal of Pathology, vol. 157, no. 2, pp. 377-384, 2000. 
[41] K. Pulford, B. Falini, A. H. Banham et al., "Immune response to the ALK oncogenic tyrosine kinase in patients with anaplastic large-cell lymphoma," Blood, vol. 96, no. 4, pp. 1605-1607, 2000.

[42] R. Chiarle, C. Martinengo, C. Mastini et al., "The anaplastic lymphoma kinase is an effective oncoantigen for lymphoma vaccination," Nature Medicine, vol. 14, no. 6, pp. 676-680, 2008.

[43] W. Cheuk, R. W. Hill, C. Bacchi, M. A. Dias, and J. K. C. Chan, "Hypocellular anaplastic large cell lymphoma mimicking inflammatory lesions of lymph nodes," American Journal of Surgical Pathology, vol. 24, no. 11, pp. 1537-1543, 2000.

[44] M. U. Kuefer, A. T. Look, K. Pulford et al., "Retrovirusmediated gene transfer of NPM-ALK causes lymphoid malignancy in mice," Blood, vol. 90, no. 8, pp. 2901-2910, 1997.

[45] R. Chiarle, J. Z. Gong, I. Guasparri et al., "NPM-ALK transgenic mice spontaneously develop T-cell lymphomas and plasma cell tumors," Blood, vol. 101, no. 5, pp. 1919-1927, 2003.

[46] R. Chiarle, W. J. Simmons, H. Cai et al., "Stat3 is required for ALK-mediated lymphomagenesis and provides a possible therapeutic target," Nature Medicine, vol. 11, no. 6, pp. 623629, 2005.

[47] T. Marafioti, L. Jabri, K. Pulford, P. Brousset, D. Y. Mason, and G. Delsol, "Leucocyte-specific protein (LSP1) in malignant lymphoma and Hodgkin's disease," British Journal of Haematology, vol. 120, no. 4, pp. 671-678, 2003.

[48] E. J. Schlette, L. J. Medeiros, A. Goy, R. Lai, and G. Z. Rassidakis, "Survivin expression predicts poorer prognosis in anaplastic large-cell lymphoma," Journal of Clinical Oncology, vol. 22, no. 9, pp. 1682-1688, 2004.

[49] G. Z. Rassidakis, R. Lai, M. Herling, C. Cromwell, A. Schmitt-Graeff, and L. J. Medeiros, "Retinoblastoma protein is frequently absent or phosphorylated in anaplastic large-cell lymphoma," American Journal of Pathology, vol. 164, no. 6, pp. 2259-2267, 2004.

[50] P. Brousset, P. Rochaix, S. Chittal, H. Rubie, A. Robert, and G. Delsoil, "High incidence of Epstein-Barr virus detection in Hodgkin's disease and absence of detection in anaplastic largecell lymphoma in children," Histopathology, vol. 23, no. 2, pp. 189-191, 1993.

[51] V. Costes-Martineau, C. Delfour, S. Obled et al., "Anaplastic lymphoma kinase (ALK) protein expressing lymphoma after liver transplantation: case report and literature review," Journal of Clinical Pathology, vol. 55, no. 11, pp. 868-871, 2002.

[52] R. Morgan, B. K. Hecht, and A. A. Sandberg, "Chromosome 5 q35 breakpoint in malignant histiocytosis," New England Journal of Medicine, vol. 314, no. 20, p. 1322, 1986.

[53] R. Rimokh, J. P. Magaud, F. Berger et al., "A translocation involving a specific breakpoint (q35) on chromosome 5 is characteristic of anaplastic large cell lymphoma ('Ki-1 lymphoma')," British Journal of Haematology, vol. 71, no. 1, pp. 31-36, 1989.

[54] M. M. Le Beau, M. A. Bitter, R. A. Larson et al., "The $\mathrm{t}(2 ; 5)(\mathrm{p} 23 ; \mathrm{q} 35)$ : a recurring chromosomal abnormality in Ki1-positive anaplastic large cell lymphoma," Leukemia, vol. 3, no. 12, pp. 866-870, 1989.

[55] D. Y. Mason, C. Bastard, R. Rimokh et al., "CD30-positive large cell lymphomas ('Ki-1 lymphoma') are associated with a chromosomal translocation involving 5q35," British Journal of Haematology, vol. 74, no. 2, pp. 161-168, 1990.
[56] M. A. Bitter, W. A. Franklin, R. A. Larson et al., "Morphology in Ki-1(CD30)-positive non-Hodgkin's lymphoma is correlated with clinical features and the presence of a unique chromosomal abnormality, t(2;5)(p23;q35)," American Journal of Surgical Pathology, vol. 14, no. 4, pp. 305-316, 1990.

[57] S. W. Morris, M. N. Kirstein, M. B. Valentine et al., "Fusion of a kinase gene, ALK, to a nucleolar protein gene, NPM, in nonHodgkin's lymphoma," Science, vol. 263, no. 5151, pp. 12811284, 1994.

[58] R. H. Palmer, E. Vernersson, C. Grabbe, and B. Hallberg, "Anaplastic lymphoma kinase: signalling in development and disease," Biochemical Journal, vol. 420, no. 3, pp. 345-361, 2009.

[59] M. Shiota, J. Fujimoto, M. Takenaga et al., "Diagnosis of $\mathrm{t}(2 ; 5)(\mathrm{p} 23 ; \mathrm{q} 35)$-associated Ki-1 lymphoma with immunohistochemistry," Blood, vol. 84, no. 11, pp. 3648-3652, 1994.

[60] B. Falini, S. Pileri, P. L. Zinzani et al., "ALK ${ }^{+}$lymphoma: clinico-pathological findings and outcome," Blood, vol. 93, no. 8, pp. 2697-2706, 1999.

[61] B. Falini and D. Y. Mason, "Proteins encoded by genes involved in chromosomal alterations in lymphoma and leukemia: clinical value of their detection by immunocytochemistry," Blood, vol. 99, no. 2, pp. 409-426, 2002.

[62] B. Falini, I. Nicoletti, N. Bolli et al., "Translocations and mutations involving the nucleophosmin (NPM1) gene in lymphomas and leukemias," Haematologica, vol. 92, no. 4, pp. 519-532, 2007.

[63] J. Cools, I. Wlodarska, R. Somers et al., "Identification of novel fusion partners of ALK, the anaplastic lymphoma kinase, in anaplastic large-cell lymphoma and inflammatory myofibroblastic tumor," Genes Chromosomes and Cancer, vol. 34, no. 4, pp. 354-362, 2002.

[64] D. Stachurski, P. M. Miron, S. Al-Homsi et al., "Anaplastic lymphoma kinase-positive diffuse large B-cell lymphoma with a complex karyotype and cryptic $3^{\prime}$ ALK gene insertion to chromosome 4 q22-24," Human Pathology, vol. 38, no. 6, pp. 940-945, 2007.

[65] L. Lamant, F. Meggetto, T. A. Saati et al., "High incidence of the $\mathrm{t}(2 ; 5)(\mathrm{p} 23 ; \mathrm{q} 35)$ translocation in anaplastic large cell lymphoma and its lack of detection in Hodgkin's disease. Comparison of cytogenetic analysis, reverse transcriptasepolymerase chain reaction, and P-80 immunostaining," Blood, vol. 87, no. 1, pp. 284-291, 1996.

[66] I. Salaverria, S. Beà, A. Lopez-Guillermo et al., "Genomic profiling reveals different genetic aberrations in systemic ALKpositive and ALK-negative anaplastic large cell lymphomas," British Journal of Haematology, vol. 140, no. 5, pp. 516-526, 2008.

[67] M. A. Thompson, J. Stumph, S. E. Henrickson et al., "Differential gene expression in anaplastic lymphoma kinasepositive and anaplastic lymphoma kinase-negative anaplastic large cell lymphomas," Human Pathology, vol. 36, no. 5, pp. 494-504, 2005.

[68] P. P. Piccaluga, C. Agostinelli, A. Califano et al., "Gene expression analysis of peripheral $\mathrm{T}$ cell lymphoma, unspecified, reveals distinct profiles and new potential therapeutic targets," Journal of Clinical Investigation, vol. 117, no. 3, pp. 823-834, 2007.

[69] L. Lamant, A. de Reyniès, M. M. Duplantier et al., "Geneexpression profiling of systemic anaplastic large-cell lymphoma reveals differences based on ALK status and two distinct morphologic ALK ${ }^{+}$subtypes," Blood, vol. 109, no. 5, pp. 2156-2164, 2007. 
[70] R. Piva, L. Agnelli, E. Pellegrino et al., "Gene expression profiling uncovers molecular classifiers for the recognition of anaplastic large-cell lymphoma within peripheral T-cell neoplasms," Journal of Clinical Oncology, vol. 28, no. 9, pp. 1583-1590, 2010.

[71] M. Fraga, P. Brousset, D. Schlaifer et al., "Bone marrow involvement in anaplastic large cell lymphoma: immunohistochemical detection of minimal disease and its prognostic significance," American Journal of Clinical Pathology, vol. 103, no. 1, pp. 82-89, 1995.

[72] L. Mussolin, M. Pillon, E. S. d'Amore et al., "Prevalence and clinical implications of bone marrow involvement in pediatric anaplastic large cell lymphoma," Leukemia, vol. 19, no. 9, pp. 1643-1647, 2005.

[73] M. Kalinova, L. Krskova, H. Brizova, E. Kabickova, T. Kepak, and R. Kodet, "Quantitative PCR detection of NPM/ALK fusion gene and CD30 gene expression in patients with anaplastic large cell lymphoma-residual disease monitoring and a correlation with the disease status," Leukemia Research, vol. 32, no. 1, pp. 25-32, 2008.

[74] M. Shiota, S. Nakamura, R. Ichinohasama et al., "Anaplastic large cell lymphomas expressing the novel chimeric protein p80(NPM/ALK): a distinct clinicopathologic entity," Blood, vol. 86, no. 5, pp. 1954-1960, 1995.

[75] S. Ascani, P. L. Zinzani, F. Gherlinzoni et al., "Peripheral T-cell lymphomas. Clinico-pathologic study of 168 cases diagnosed according to the R.E.A.L. classification," Annals of Oncology, vol. 8, no. 6, pp. 583-592, 1997.

[76] J. M. Vose, J. Armitage, and D. Weisenburger, "International peripheral T-cell and natural killer/T-cell lymphoma study: pathology findings and clinical outcomes," Journal of Clinical Oncology, vol. 26, no. 25, pp. 4124-4130, 2008.

[77] F. d'Amore, E. Jantunen, and T. Relander, "Hemopoietic stem cell transplantation in T-cell malignancies: who, when, and how?" Current Hematologic Malignancy Reports, vol. 4, no. 4, pp. 236-244, 2009.

[78] R. L. ten Berge, P. C. de Bruin, J. J. Oudejans, G. J. Ossenkoppele, P. van der Valk, and C. J. L. M. Meijer, "ALKnegative anaplastic large-cell lymphoma demonstrates similar poor prognosis to peripheral T-cell lymphoma, unspecified," Histopathology, vol. 43, no. 5, pp. 462-469, 2003.

[79] W. Wan, M. S. Albom, L. Lu et al., "Anaplastic lymphoma kinase activity is essential for the proliferation and survival of anaplastic large-cell lymphoma cells," Blood, vol. 107, no. 4, pp. 1617-1623, 2006.

[80] A. V. Galkin, J. S. Melnick, S. Kim et al., "Identification of NVP-TAE684, a potent, selective, and efficacious inhibitor of NPM-ALK," Proceedings of the National Academy of Sciences of the United States of America, vol. 104, no. 1, pp. 270-275, 2007.

[81] H. M. Amin, L. J. Medeiros, Y. Ma et al., "Inhibition of JAK3 induces apoptosis and decreases anaplastic lymphoma kinase activity in anaplastic large cell lymphoma," Oncogene, vol. 22, no. 35, pp. 5399-5407, 2003.

[82] H. M. Amin, T. J. McDonnell, Y. Ma et al., "Selective inhibition of STAT3 induces apoptosis and G cell cycle arrest in ALKpositive anaplastic large cell lymphoma," Oncogene, vol. 23, no. 32, pp. 5426-5434, 2004.

[83] L. Qiu, R. Lai, Q. Lin et al., "Autocrine release of interleukin-9 promotes Jak3-dependent survival of $\mathrm{ALK}^{+}$anaplastic largecell lymphoma cells," Blood, vol. 108, no. 7, pp. 2407-2415, 2006.

[84] P. P. Piccaluga, C. Agostinelli, P. L. Zinzani, M. Baccarani, R. D. Favera, and S. A. Pileri, "Expression of platelet-derived growth factor receptor $\alpha$ in peripheral T-cell lymphoma not otherwise specified," Lancet Oncology, vol. 6, no. 6, p. 440, 2005.

[85] P. P. Piccaluga, C. Agostinelli, A. Califano et al., "Gene expression analysis of angioimmunoblastic lymphoma indicates derivation from $\mathrm{T}$ follicular helper cells and vascular endothelial growth factor deregulation," Cancer Research, vol. 67, no. 22, pp. 10703-10710, 2007.

[86] Y. Huang, A. de Reyniès, L. de Leval et al., "Gene expression profiling identifies emerging oncogenic pathways operating in extranodal NK/T-cell lymphoma, nasal type," Blood, vol. 115, no. 6, pp. 1226-1237, 2010.

[87] B. Falini, A. Bolognesi, L. Flenghi et al., "Response of refractory Hodgkin's disease to monoclonal anti-CD30 immunotoxin," Lancet, vol. 339, no. 8803, pp. 1195-1196, 1992.

[88] P. L. Tazzari, A. Bolognesi, D. de Totero et al., "Ber-H2 (antiCD30)-saporin immunotoxin: a new tool for the treatment of Hodgkin's disease and CD30+ lymphoma: in vitro evaluation," British Journal of Haematology, vol. 81, no. 2, pp. 203-211, 1992.

[89] L. Pasqualucci, M. Wasik, B. A. Teicher et al., "Antitumor activity of anti-CD30 immunotoxin (Ber-H2/saporin) in vitro and in severe combined immunodeficiency disease mice xenografted with human $\mathrm{CD}^{+} 0^{+}$anaplastic large-cell lymphoma," Blood, vol. 85, no. 8, pp. 2139-2146, 1995.

[90] W. Pfeifer, E. Levi, T. Petrogiannis-Haliotis, L. Lehmann, Z. Wang, and M. E. Kadin, "A murine xenograft model for human $\mathrm{CD} 30+$ anaplastic large cell lymphoma: successful growth inhibition with an anti-CD30 antibody (HeFi-1)," American Journal of Pathology, vol. 155, no. 4, pp. 1353-1359, 1999.

[91] M. A. Fanale and A. Younes, "Monoclonal antibodies in the treatment of non-hodgkin's lymphoma," Drugs, vol. 67, no. 3, pp. 333-350, 2007.

[92] L. Ho, U. Aytac, L. C. Stephens et al., "In vitro and in vivo antitumor effect of the anti-CD26 monoclonal antibody 1F7 on human CD30+ anaplastic large cell T-cell lymphoma Karpas 299," Clinical Cancer Research, vol. 7, no. 7, pp. 20312040, 2001. 


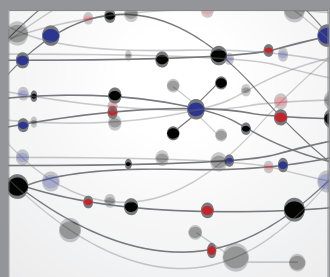

The Scientific World Journal
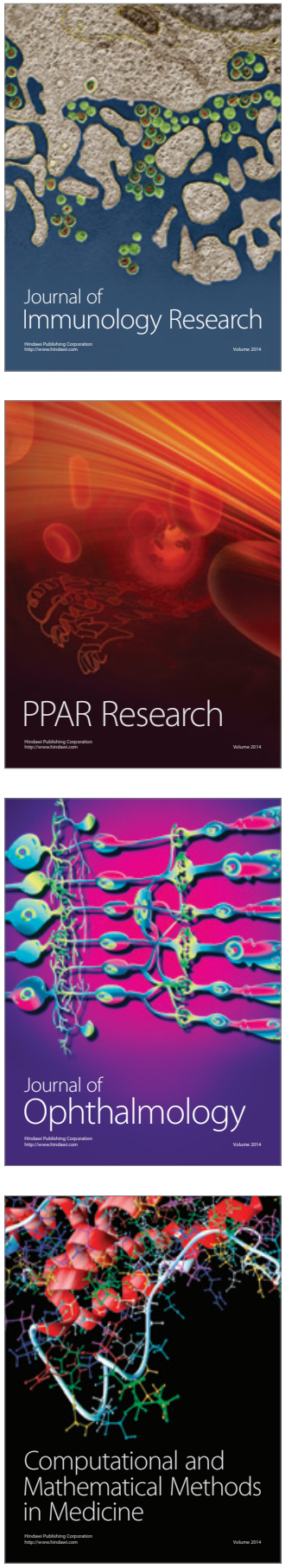

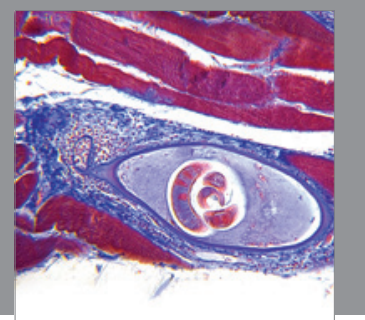

Gastroenterology

Research and Practice
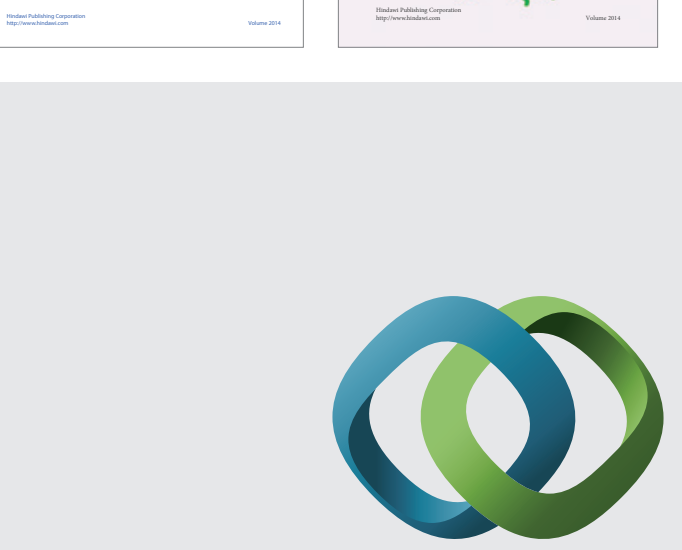

\section{Hindawi}

Submit your manuscripts at

http://www.hindawi.com
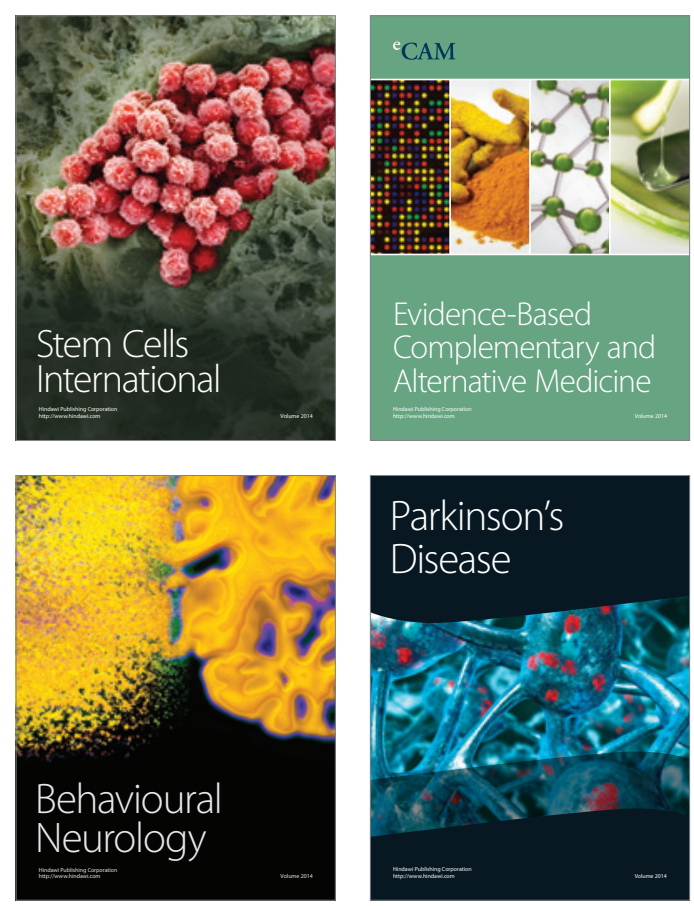

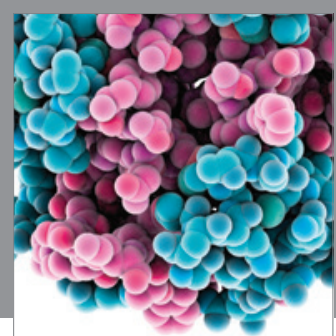

Journal of
Diabetes Research

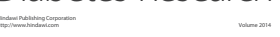

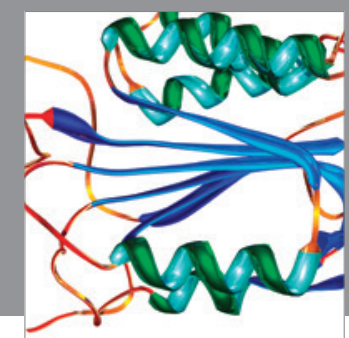

Disease Markers
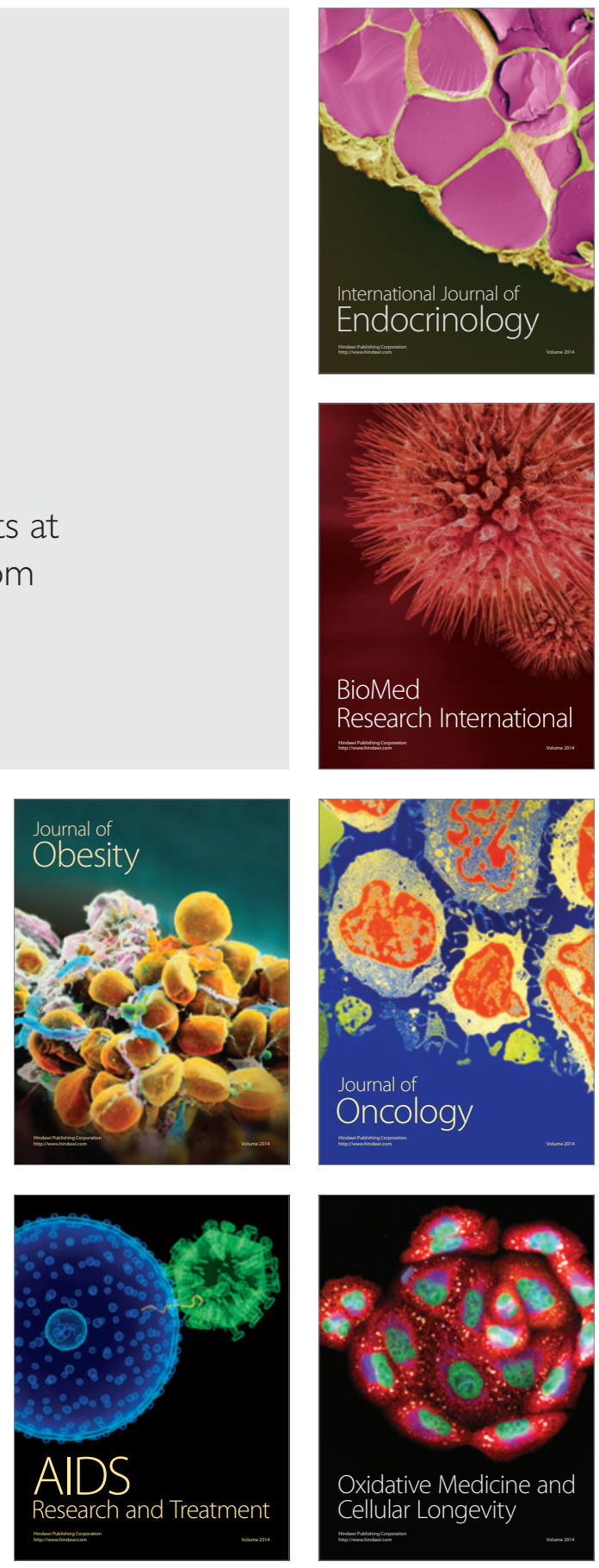